\title{
Radial Force Control for Triple Three-Phase Sectored SPM Machines. Part II: Open Winding Fault Tolerant Control
}

\author{
G. Sala, D. Gerada, C. Gerada, IEEE Member, A. Tani
}

\begin{abstract}
A new advanced fault tolerant control technique for a triple three-phase Surface Permanent Magnet (SPM) machine is investigated in this paper. The machine has a ninephase winding arranged in three sectors and supplied by three different Voltage Source Inverters (VSIs). The proposed current control technique is firstly exploited to avoid the radial force appearance in case of open winding of one machine sector. Then, the radial force fault tolerant control is improved to compensate for a bearing fault or another source of radial force in this open winding condition. Finite element simulations are used to validate the two proposed control techniques. Finally, advantages and drawbacks of the solution are highlighted.
\end{abstract}

Index Terms-Analytical models, brushless machines, circuit faults, fault tolerance, fault tolerant systems, force, force control, machine vector control, permanent magnet machines.

\section{INTRODUCTION}

$\mathrm{M}$ ULTIPHASE machines, and even more the multi three-phase topologies, have been proposed as a possible solution to increase the reliability of critical systems. This is the case of More Electric Aircraft (MEA) applications, where machine fault tolerant designs and controls are essential to meet the safety requirements. The multiphase control allows increasing the machine performance, owing to the increased degrees of freedom related to the higher number of independent currents. The additional degrees of freedom can be also exploited to overcome machine faults and/or detect them. The idea is to have not only a redundant number of phases, but to develop a control which adapts to the machine fault conditions in order to optimize the machine behaviour [1]-[3]. In this paper this concept is referred to as fault tolerant control.

Multiphase machines can be wound in different ways, depending on the machine topology and control requests. A typical solution is the multi three-phase one, where there is a number of three-phase windings fed by independent VSIs. Among the multi three-phase solutions, a sectored one is analyzed, where the sectored machine concept refers to a design in which the three-phase windings are not only supplied by different VSIs, but are also located in a different stator area (sectors) [4]-[5].

G. Sala and A. Tani are with the Department of Electric, Electronic and Information Engineering, Bologna University, Bologna, Italy (e-mail: giacomo.sala5@unibo.it; angelo.tani@unibo.it).

C. Gerada and D. Gerada are with the Power Electronics, Machines and Control Group, Department of Electrical and Electronic Engineering, The University of Nottingham, Nottingham, NG7 2RD, U.K. (e-mail: chris.gerada@nottingham.ac.uk; david.gerada@nottingham.ac.uk).
The sectored design shows reduced mutual inductances between the phases of different sectors, due to the absence of overlapping between them. Because the mutual inductance analysis is one of the main parameter used to compare different machine design in terms of short circuit and open winding fault criticalities [6], sectored machines are considered a suitable solution for fault tolerant applications.

However, sectored machines show a worst behaviour in case of one inverter opening, when compared to the symmetrically wound ones. Specifically, there is an undesired radial force that appears due to the asymmetrical magnetomotive force distribution [6]-[8]. This radial force can produce vibrations and cause bearing damages.

The sectored machines are often double three-phase ones, but also three, four or a higher number of sectors can be designed. In this paper, a triple three-phase winding machine is investigated, since this is the minimum number of threephase sectors that allows defining a fault tolerant radial force control in case of three-phase open winding. The analysed machine drawing and winding are shown in Fig.1.

With the proposed control technique, when one winding is open, the machine is compensated for the appearing radial force. Furthermore, the radial force can be still controlled to a reference value, allowing the possibility to release the bearings from the rotor weight or other sources of force. The radial force control is based on the multi space vector approach, as in [9], rather than an equivalent magnetic circuit or a semi-analytical FE deduction, as in [5] and [10]-[14].

This paper is the second part of a work on the radial force control for triple three-phase sectored SPM machines. In the first part (Part I [15]) the machine model of the machine and the relative radial force control technique are presented. In this second part (Part II) a fault tolerant control in case of one three-phase sector open winding fault is analysed.

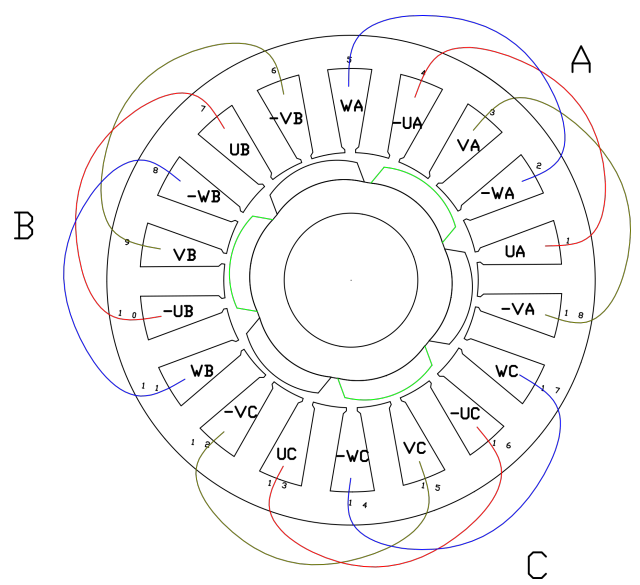

Fig. 1. Sectored triple three-phase SPM machine. 
The machine model developed in [15] is summarized in Section II and III, showing how to manage the multi space vector control and the back-ems. In Section IV the force fault tolerant control technique of the radial force is explained. FE simulation results are reported in Section $\mathrm{V}$, showing the possibility to compensate for the radial force appearing and control the radial force in case of one sector open winding fault.

\section{SPace Vector Representation of Triple ThreE- PHASE SECTORED MACHINE MODEL}

To model the analyzed machine, it is possible to define a redundant transformation as

$$
\bar{z}_{\rho}=2 / 9 \sum_{x=1}^{18} y_{x} e^{j \rho \psi_{x}}, \quad[\rho=0,1,2, . ., \infty],
$$

where $\psi_{x}=2 \pi / 18(x-1)$ is the magnetic axis of the winding starting from the $x$-th slot and ending in the $(x+3)$-th slot.

The respective inverse-transformation is

$$
y_{x}=\frac{z_{0}}{4}+\frac{z_{9}}{4}(-1)^{(x-1)}+\frac{1}{2} \sum_{\rho=1}^{8} \mathfrak{R}\left\{z_{\rho} e^{-j \rho \psi_{x}}\right\},
$$

It means that for $\mathrm{x}=3,4,5,9,10,11,15,16$ and 17 the $x$-th component is null $\left(y_{x}=0\right)$.

For each three phase sub-system the transformation is

$$
\begin{aligned}
& \bar{z}_{X}=2 / 3\left(y_{U X}+y_{V X} \bar{\alpha}_{3 P}+y_{W X} \bar{\alpha}_{3 P}{ }^{2}\right), \\
& z_{X 0}=2 / 3\left(y_{U X}+y_{V X}+y_{W X}\right),
\end{aligned}
$$

and the related inverse - transformation is

$$
\begin{aligned}
& y_{U X}=z_{X 0} / 2+\mathfrak{R}\left\{\bar{z}_{X} \bar{\alpha}_{3 P}\right. \\
& y_{V X}=z_{X 0} / 2+\mathfrak{R}\left\{\bar{z}_{X} \bar{\alpha}_{3 P}^{2}\right. \\
& y_{W X}=z_{X 0} / 2+\mathfrak{R}\left\{\bar{z}_{X} \bar{\alpha}_{3 P}\right\},
\end{aligned},
$$

where $\bar{\alpha}_{3 P}=\exp (j 2 \pi / 3)$ and $\mathrm{X}=\mathrm{A}, \mathrm{B}, \mathrm{C}$.

Because the analyzed machine has a star connection for each three phase subsystem, $i_{X 0}$ is zero, and the current zero sequence $z_{X 0}$ can be neglected. The voltage control has a non-zero sequence value, but $v_{X 0}$ depends on the modulation technique of each inverter, and not on the machine control. This allows introducing the transformation

$$
\begin{aligned}
& \bar{z}_{M}=1 / 3\left(\bar{z}_{A}+\bar{z}_{B} \bar{\alpha}_{3 P}+\bar{z}_{C} \bar{\alpha}_{3 P}{ }^{2}\right), \\
& \bar{z}_{N}=1 / 3\left(\bar{z}_{A}+\bar{z}_{B} \bar{\alpha}_{3 P}{ }^{2}+\bar{z}_{C} \bar{\alpha}_{3 P}\right), \\
& \bar{z}_{S}=1 / 3\left(\bar{z}_{A}+\bar{z}_{B}+\bar{z}_{C}\right),
\end{aligned}
$$

and the two set of transformation

$$
\begin{aligned}
& z_{0}=2 / 3\left(\bar{z}_{S}+\bar{z}_{S}^{*}\right), \\
& \bar{z}_{3}=\bar{z}_{S}, \\
& \bar{z}_{6}=1 / 3\left(2 \bar{z}_{S}-\bar{z}_{S}\right), \\
& \bar{z}_{9}=0,
\end{aligned}
$$

and

$$
\begin{aligned}
& \bar{z}_{1}=1 / 3\left(\bar{z}_{M} c_{m 1}+\bar{z}_{N}^{*} c_{n 1}\right), \\
& \bar{z}_{2}=1 / 3\left(\bar{z}_{N} c_{m 2}+\bar{z}_{M} c_{n 2}\right),
\end{aligned}
$$

$$
\begin{aligned}
& \bar{z}_{4}=1 / 3\left(\bar{z}_{M} c_{m 2}+\bar{z}_{N}^{*} c_{n 4}\right), \\
& \bar{z}_{5}=1 / 3\left(\bar{z}_{N} c_{m 1}+\bar{z}_{M}^{*} c_{n 5}\right), \\
& \bar{z}_{7}=1 / 3\left(\bar{z}_{N} c_{n 1}+\bar{z}_{M}^{*} c_{n 5}\right), \\
& \bar{z}_{8}=1 / 3\left(\bar{z}_{N} c_{n 2}+\bar{z}_{M}^{*} c_{n 4}\right),
\end{aligned}
$$

with $\bar{\alpha}$ equal to $\exp (j 2 \pi / 18)$, “*” used to define the complex conjugate, and the constants $c_{m \rho}$ and $c_{n \rho}$ defined as:

$$
c_{m \rho}=1-\bar{\alpha}^{(-6-\rho)}-\bar{\alpha}^{(-12+\rho)}, c_{n \rho}=1-\bar{\alpha}^{(6-\rho)}-\bar{\alpha}^{(12+\rho)} .
$$

\section{Model And Control of A Triple Three-Phase SECTORED SPM MACHINE}

Modeling the machine in mechanical angles and with the time dependence implicit, it is possible to approximately define a torque control independent from the radial force one [15]. The resulting torque equation is

$$
T_{M}=\frac{27}{4} L_{0 P M} \mathfrak{J}\left\{\bar{i}_{3} e^{-j 3 \theta_{m}}\right\},
$$

with $L_{0 P M}=12 \frac{4}{9 \pi} N_{C} L R \frac{B_{P M r} \delta_{P M}}{\delta}$,

where $\theta_{m}$ is the rotor angular position, $N_{c}$ the turns number for each phase, $L$ the machine active length, $R$ the average air-gap radius, $\delta$ and $\delta_{P M}$ the air-gap and magnet thicknesses, $B_{P M r}$ the residual flux density.

Instead, the radial force can be expressed as

$$
\bar{F}=K_{2} \bar{i}_{2} e^{j 3 \theta_{m}}+K_{4} \bar{i}_{4} e^{-j 3 \theta_{m}},
$$

where the coefficients $K_{2}$ and $K_{4}$ are defined as

$$
K_{h}=L R \frac{18 N_{c}}{\pi} \frac{B_{P M r} \delta_{P M}}{\delta^{2}} \frac{\sin \left(\frac{h \pi}{6}\right)}{h} .
$$

The voltage space vector equations are defined to show the possibility to control the torque and the radial force. For the $\rho$-th space voltage vector, defined in (6)-(7),

$$
\bar{v}_{\rho}=r_{s} \bar{i}_{\rho}+l_{d s} \frac{d \bar{i}_{\rho}}{d t}+\frac{d \bar{\phi}_{\rho}}{d t},
$$

where $r_{s}$ is the phase resistance, $l_{d s}$ the phase leakage inductance.

To well control an SPM machine it is also required to compensate for the back-EMF in each space. This is possible if the model can relate the space vectors of the linked fluxes to the current ones. The generic $\rho$ - space linked flux space vectors can be described as

$$
\bar{\phi}_{\rho}=\sum_{h=0}^{9} L_{\rho, h} \bar{i}_{h}+\bar{\phi}_{P M, \rho},[\rho=0,1,2, ., \infty],
$$

where $L \rho, h$ is the inductance between the $h$-th and the $\rho$-th space, and $\bar{\phi}_{P M, \rho}$ is the $\rho$-th space vector of the linked fluxes caused by the permanent magnets. The space vector of the linked fluxes, taking into account only the main permanent magnet field harmonic and the armature field harmonics till the $9^{\text {th }}$ one, are: 


$$
\begin{aligned}
& \phi_{0}=L_{03} \Re\left\{\bar{i}_{3}\right\}+L_{0 P M} 6 \frac{e^{j 3 \theta_{m}}}{9}, \\
& \bar{\phi}_{1}=L_{1,1} \bar{i}_{1}+L_{1,2} \bar{i}_{2}^{*}+L_{1,4} \bar{i}_{4}+L_{1,8} \bar{i}_{8}^{*}, \\
& \bar{\phi}_{2}=L_{2,2} \bar{i}_{2}+L_{2,1} \bar{i}_{1}^{*}+L_{2,5} \bar{i}_{5}+L_{2,7} \bar{i}_{7}^{*}, \\
& \bar{\phi}_{3}=L_{3,3} \bar{i}_{3}+L_{0 P M} \frac{e^{j 3 \theta_{m}}}{2}, \\
& \bar{\phi}_{4}=L_{4,4} \bar{i}_{4}+L_{4,1} \bar{i}_{1}+L_{4,5} \bar{i}_{5}^{*}+L_{4,7} \bar{i}_{7}, \\
& \bar{\phi}_{5}=L_{5,5} \bar{i}_{5}+L_{5,2} \bar{i}_{2}+L_{5,4} \bar{i}_{4}^{*}+L_{5,8} \bar{i}_{8}, \\
& \bar{\phi}_{6}=L_{6,6} \bar{i}_{6}+L_{6,6-3} \bar{i}_{3}+L_{6,6-9} \bar{i}_{3}^{*}, \\
& \bar{\phi}_{7}=L_{7,7} \bar{i}_{7}+L_{7,2} \bar{i}_{2}^{*}+L_{7,4} \bar{i}_{4}+L_{7,10} \bar{i}_{8}^{*}, \\
& \bar{\phi}_{8}=L_{8,8} \bar{i}_{8}+L_{8,1} \bar{i}_{1}^{*}+L_{8,5} \bar{i}_{5}+L_{8,11} \bar{i}_{7}^{*}, \\
& \bar{\phi}_{9}=0,
\end{aligned}
$$

with:

$$
\begin{aligned}
& L_{h, h}=9\left[K l_{h}+K l_{18-h}\right], \\
& L_{h, h-3}=L_{h, 3-h}=6\left[K l_{h-3}\right], \\
& L_{h, h+3}=6\left[K l_{3+h}+K l_{15-h}\right], \\
& L_{h, 9-h}=-3\left[K l_{9-h}\right],
\end{aligned}
$$

and $K l_{z}=\frac{2}{\pi} N_{c}^{2} \mu_{0} \frac{L R}{\delta}\left(\sin \left(z \frac{\pi}{6}\right) / z\right)^{2}$.

To control the current space vector 3 , and so the torque, it is sufficient to analyze (15) as in standard machine control. Instead, to control the space vectors 2 and 4 , and so the radial force, it is needed to analyze (14) and (16), which also depend on the $1^{\text {st }}, 5^{\text {th }}$ and $7^{\text {th }}$ space vectors. By (7) it is possible to evaluate all the current space vectors by $\bar{i}_{M}$ and $\bar{i}_{N}$. In this way, the torque and force control define the desired $2^{\text {nd }}, 3^{\text {rd }}$ and $4^{\text {th }}$ current space vectors. By (6) and (7) $\bar{i}_{M}, \bar{i}_{N}$ and $\bar{i}_{S}$ are evaluated, and with the same equations the calculated $1^{\text {st }}, 5^{\text {th }}$ and $7^{\text {th }}$ space vectors are used to estimate the back-EMF in the controlled spaces. By the back EMF compensation, the $2^{\text {nd }}, 3^{\text {rd }}$ and $4^{\text {th }}$ current space vectors can be controlled by standard PI regulators.

\section{RADIAL ForCE FAULt TOLERANT CONTROL FOR ONE SECTOR OPEN WINDING FAULT}

The open winding fault of one three-phase sector is analyzed in this paper, and the fault tolerant control is generalized for all the possible faults (of sector A, B or C).

A sectored SPM triple three-phase machine could be controlled as three redundant machines, with still a standard symmetrical control. However, when one sector windings are opened, a radial force appears [8]. To overcome this problem, in this paper a fault tolerant technique to compensate for this radial force, and control it if desired, is proposed. The fault tolerant algorithm is based on new relations for the main current space vectors $\bar{i}_{M}$ and $\bar{i}_{N}$, while $\bar{i}_{S}$ is controlled independently to reach the reference torque. The most important relation between the main current space vectors $\left(\bar{i}_{M}, \bar{i}_{N}\right.$ and $\left.\bar{i}_{S}\right)$ and the standard three-phase ones $\left(\bar{i}_{X}\right.$, with $\left.\mathrm{X}=\mathrm{A}, \mathrm{B}, \mathrm{C}\right)$ is

$$
\bar{i}_{N}=\bar{c}_{N S} \bar{i}_{S}+\bar{c}_{N M} \bar{i}_{M}+\bar{c}_{N X} \bar{i}_{X}
$$

where

$\bar{c}_{N S}=-\bar{\alpha}_{3 P}{ }^{-s_{x}}, \quad \bar{c}_{N M}=-\bar{\alpha}_{3 P}{ }^{s_{x}}$ and $\bar{c}_{N X}=\bar{\alpha}_{3 P}{ }^{-s_{x}}$,

with $S_{A}=0, S_{B}=1, S_{C}=2$ the $S_{X}$ values related to the $\mathrm{X}$ sector.

The $\mathrm{X}$ sector open winding relation is obtained by (22) when the $\mathrm{X}$ sector current vector is zero $\left(\bar{i}_{X}=0\right)$. From (22) it is possible to evaluate the radial force appearing in case of fault, because (22) defines the constraint between the current space vectors $\bar{i}_{M}$ and $\bar{i}_{N}$. Furthermore, introducing (22) in (7) and (7) in (9), it is possible to define the generic radial force fault tolerant equation as

$$
\bar{i}_{M}=\frac{3 \bar{F}^{*}+\bar{K}_{F} \bar{F}+\bar{K}_{S c} \bar{i}_{S}^{*}+\bar{K}_{S} \bar{i}_{S}}{\bar{K}_{D}},
$$

where $\bar{i}_{S}$ is related to the torque control and $\bar{F}$ is the reference radial force. The parameters in (23) are defined as

$$
\begin{aligned}
& \bar{K}_{F}=-\frac{\left[K_{2} c_{n 2} e^{-j 3 \theta_{m}}+K_{4} c_{m 2} e^{j 3 \theta_{m}}\right] 3}{\left[K_{2} c_{m 2} e^{j 3 \theta_{m}}+K_{4} c_{n 4} e^{-j 3 \theta_{m}}\right] \bar{c}_{N M}^{*},} \\
& \bar{K}_{S c}=\left[K_{2} c_{n 2} e^{-j 3 \theta_{m}}+K_{4} c_{m 2} e^{j 3 \theta_{m}}\right] \frac{\bar{c}_{N S}^{*}}{\bar{c}_{N M}^{*}}, \\
& \bar{K}_{S}=-\left[K_{2} c_{m 2} e^{-j 3 \theta_{m}}+K_{4} c_{n 4} e^{j 3 \theta_{m}}\right] \bar{c}_{N M}, \\
& \bar{K}_{D}=\left[K_{2} c_{m 2} e^{-j 3 \theta_{m}}+K_{4} c_{n 4} e^{j 3 \theta_{m}}\right] \bar{c}_{N M}+ \\
& -\frac{\left[K_{2} c_{n 2} e^{-j 3 \theta_{m}}+K_{4} c_{m 2} e^{j 3 \theta_{m}}\right]\left[K_{2} c_{n 2} e^{j 3 \theta_{m}}+K_{4} c_{m 2} e^{-j 3 \theta_{m}}\right] .}{\left[K_{2} c_{m 2} e^{j 3 \theta_{m}}+K_{4} c_{n 4} e^{-j 3 \theta_{m}}\right] \bar{c}_{N M}^{*}} .
\end{aligned}
$$

To avoid the radial force drawback of a faulty triple threephase machine, the reference force $\bar{F}$ in (23) must be easily set to zero. In this case $\bar{i}_{M}$ and $\bar{i}_{N}$ are related only to $\bar{i}_{S}$ (to the torque control). If it is needed to control the radial force, $\bar{i}_{M}$ and $\bar{i}_{N}$ are still defined by (22) and (23).

It should be noticed that when the machine is healthy, the force control can be optimized with the best choice of $\bar{i}_{M}$ and $\bar{i}_{N}$, that means $\bar{i}_{2}$ and $\bar{i}_{4}$. Instead, in case of one sector open winding the decrease of degrees of freedom does not allow anymore a choice in the radial force control, because $\bar{i}_{M}$ and $\bar{i}_{N}$ are completely defined by (22) and (23). Furthermore, if (22) and (23) are introduced in (7), the current space vectors related to the force production $\left(\bar{i}_{2}\right.$ and $\left.\bar{i}_{4}\right)$ are no more independent from the torque control (or $\bar{i}_{S}$ ). This means that the radial force control has to adapt to the fault condition to well compensate for it.

\section{Simulation Results}

The radial force evaluation, compensation and control are evaluated by FE simulations in Magnet ${ }^{\mathrm{TM}}$ for the case of one sector open winding fault. The simulated machine main data are reported in Table I.

The radial force resulting by a finite elements simulation and the radial force evaluated by (9) in case of sectors open winding are reported in Fig. 2 (referred to as F and F E respectively). In this simulation the remaining healthy sectors are controlled with a redundant three-phase technique. This 

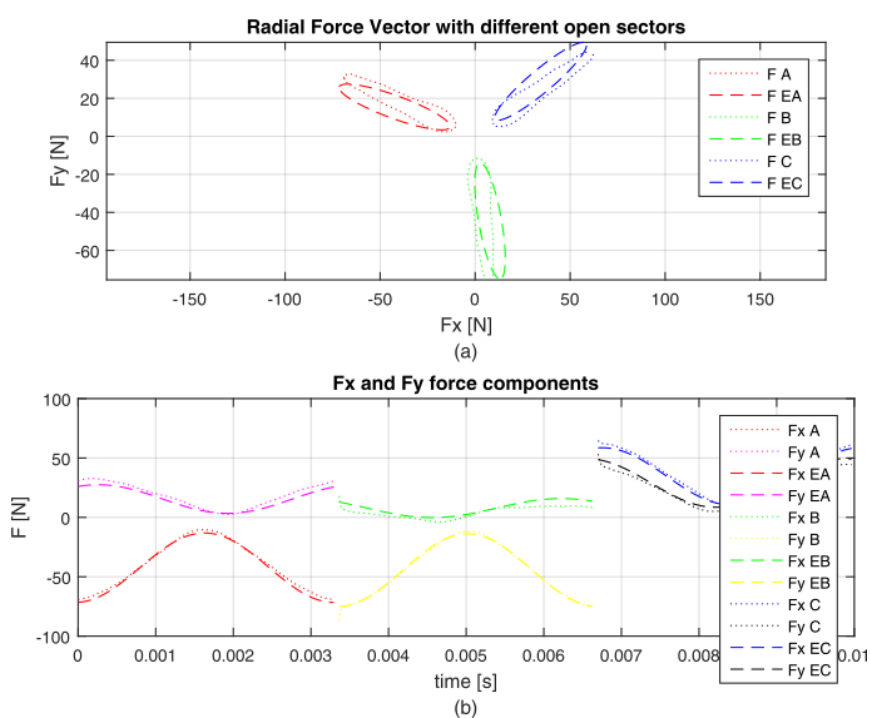

Fig. 2. Simulated radial force $(F)$ and analytical radial force evaluation (F E) in one sector open winding configurations with standard redundant three-phase current control. Force vector trajectory (a) and its $x-y$ components (b). The torque is $5[\mathrm{Nm}]$. In the legend, with $\mathrm{A}, \mathrm{B}$ and $\mathrm{C}$ (red-purple, green-yellow and blue-black) are identified the open winding conditions of the respective sectors.

means that the three-phase sectors are controlled with the same reference current $\left(\bar{i}_{A}=\bar{i}_{B}=\bar{i}_{C}=\bar{i}_{S}\right)$, and $\bar{i}_{S}$ is controlled to reach the reference torque. To reach the same torque with one sector open, the phase currents in the remaining healthy phases are increased by about $3 / 2$ times. This solution is the easiest and the most common for the sectored multi three-phase machines. The radial force vector trajectory and its x-y components are shown in Fig. 2, where the radial force for all the three sector open winding faults are presented, with different colors, at $5 \mathrm{Nm}$ torque.

The radial force evaluation is essential to understand how much this fault is critical in the analyzed machine, but also to compare the fault tolerant control with the standard one. As can be seen from Fig. 2, the radial force has a mean value related to the broken machine sector and a ripple at twice the main electrical frequency. Its mean value is of about $44 \mathrm{~N}$ and the ripple of about $65 \mathrm{~N}$ peak to peak. This can produce bearing damages and rotor vibrations. The phase currents related to this simulation are shown in Fig. 3. While the radial force appears, the torque control still works as in case of a healthy machine. The maximum phase current in the standard controlled faulty machine, in Fig. 5, is 17.3 A, when in healthy conditions it is $11.6 \mathrm{~A}$. As expected the needed current in the faulty machine is $3 / 2$ times the value of the healthy case.

The fault tolerant control, deeply discussed in this paper, allows avoiding the radial force and to control it in case of one sector three-phase open winding.

The machine behaviour in different working conditions is shown in Figs. 4 and 5 without radial force control, with regions 'a'-'d' corresponding to different time periods. The machine is firstly controlled with the standard torque control (a), then the fault happens in sector $\mathrm{A}$ (b), then it is compensated for the radial force due to the fault in (c), and finally it is compensated for the force in no load conditions $(0$ $\mathrm{Nm})$ (d). In the first fourth of the reported simulation the
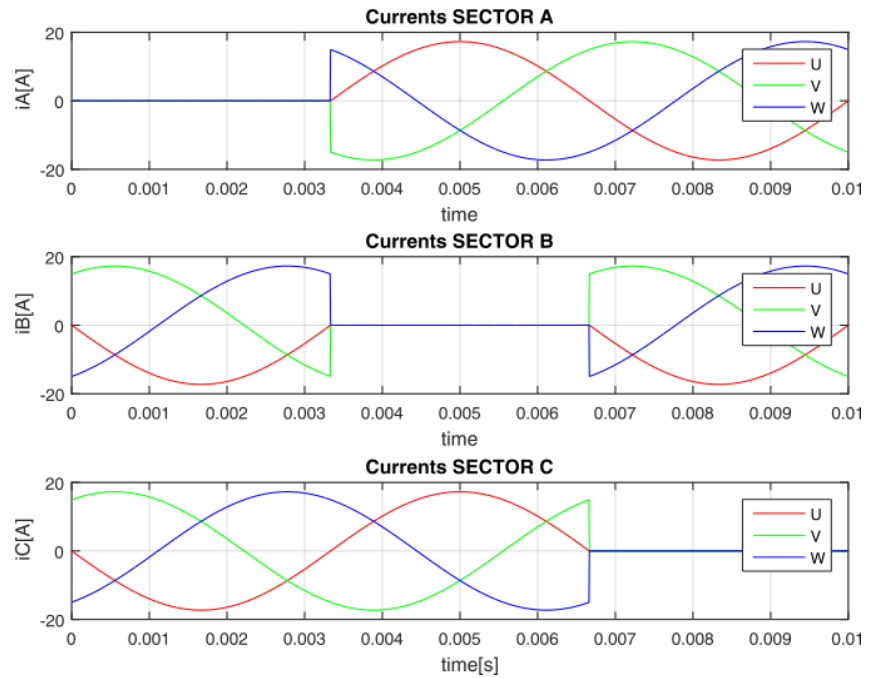

Fig. 3. Currents in one sector open winding configurations with standard redundant symmetrical three-phase current control. The torque is $5[\mathrm{Nm}]$.

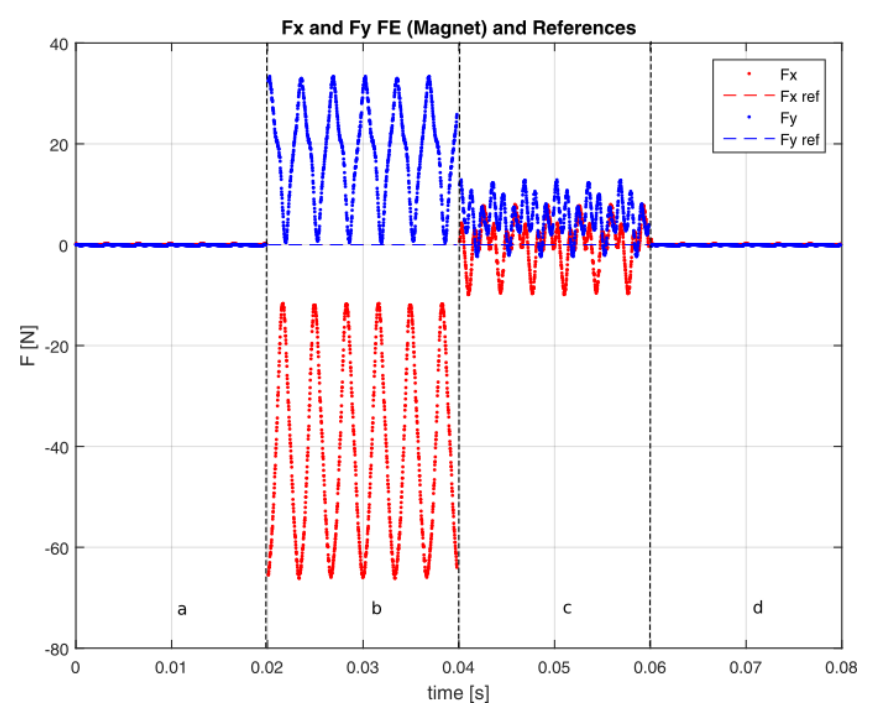

Fig. 4. FE radial force values with $5[\mathrm{Nm}]$ torque and $0[\mathrm{~N}]$ reference radial force. Healthy machine (a), standard open windings control (b), radial force compensation by fault tolerant control (c), radial force fault tolerant control at no load (d).
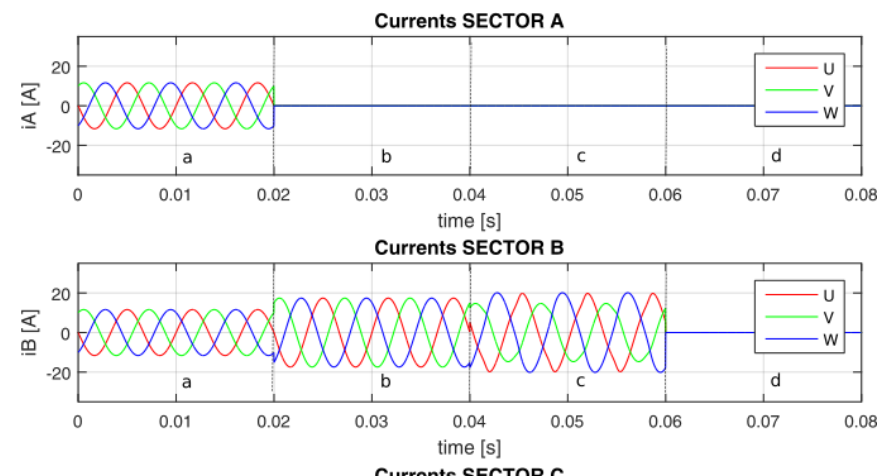

Currents SECTOR C

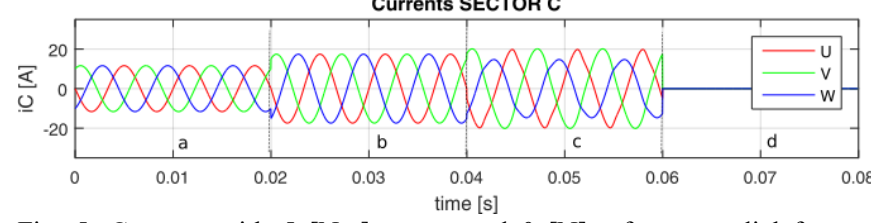

Fig. 5. Currents with $5[\mathrm{Nm}]$ torque and $0[\mathrm{~N}]$ reference radial force. Healthy machine (a), standard open windings control (b), radial force compensation by fault tolerant control (c), radial force fault tolerant control at no load (d). 
machine is healthy and it is controlled as a three-phase machine (a). As expected, the machine symmetry allows having zero radial force. The only force which appears is the rotor weight, but it is neglected in the FE simulation because it is easily evaluable (about $25 \mathrm{~N}$ in the simulated machine). Then the machine faulty behaviour is simulated when the standard control is maintained (b). The radial force in case of fault is still the same of Fig. 2. Then the machine is compensated for the radial force in an open loop control by the fault tolerant algorithm (c). The compensation is not complete, due to other radial force contributions neglected in the model. Comparing Fig. 5 (b) and (c), the compensation allows reducing the radial force mean value from 44 to $9 \mathrm{~N}$ (about 5 times), and the ripple is also significantly reduced from 65 to $11 \mathrm{~N}$ (about 6 times).

Also if the analysis of the fault tolerant radial force ripple frequencies is not a purpose of this work, it must be noted that, in the standard fault control, the main radial force ripple has a frequency of twice the main electrical frequency, while in the new fault tolerant control there are more and smaller harmonic components with higher frequencies.

Another simulation result is reported in Fig. 6 in case of a radial force reference value of $25 \mathrm{~N}$ in the vertical direction. This value is the one needed to release the bearing from the rotor weight. The currents and the torque of the same simulation are shown in Fig. 7 and Fig. 8 respectively.

From Fig. 6 it is possible to highlight how the performance of the fault tolerant radial force control is better at no load. This result is in agreement with the theory presented in this paper. The uncontrolled radial force components increase when the $3^{\text {rd }}$ space current vector, or $\bar{i}_{S}$, is controlled to produce the torque. It is also clear that the radial force control performance when the machine is faulty are lower, due to the increase of stator Joule losses and iron losses. Indeed, when the fault happens, also without considering the radial force, the currents increase of $3 / 2$ to

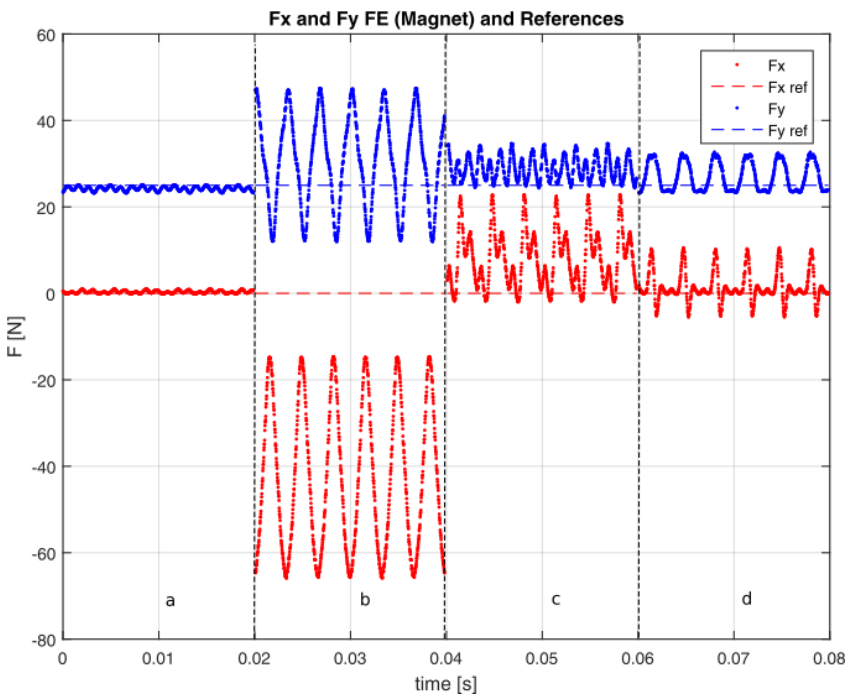

Fig. 6. FE radial force values with $5[\mathrm{Nm}]$ torque and $25[\mathrm{~N}]$ reference radial force. Healthy machine (a), standard open winding control (b), radial force compensation by fault tolerant control (c), radial force fault tolerant control at no load (d). reach the desired torque, as in Fig. 5 (b). To compensate for the toque-related radial force there is a further increase, as in Fig. 5 (c). To control the radial force to a reference value at no load, the currents increase as in Fig. 7 (d). Finally, the total currents needed at rated torque to control the radial force are as in Fig. 7 (c). As shown in Fig. 7, the radial force fault tolerant control in case of fault makes some of the healthy phases, and the respective VSI, work in an overload condition. Anyway, the condition of fault is usually a
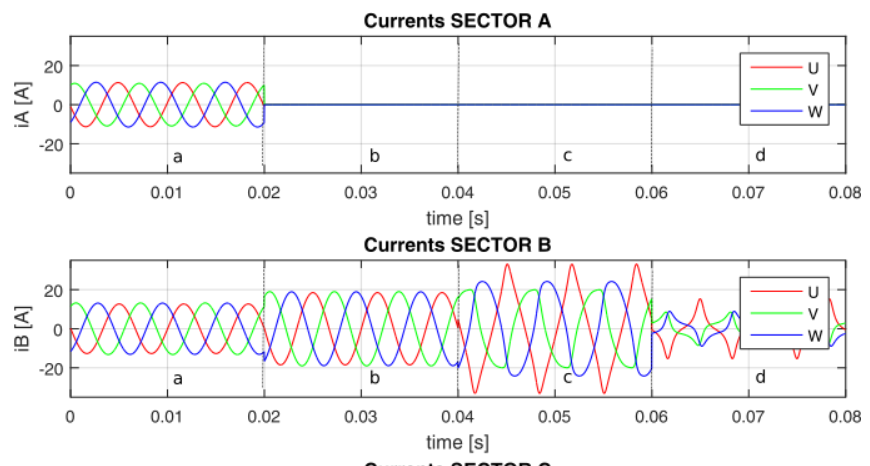

Currents SECTOR C

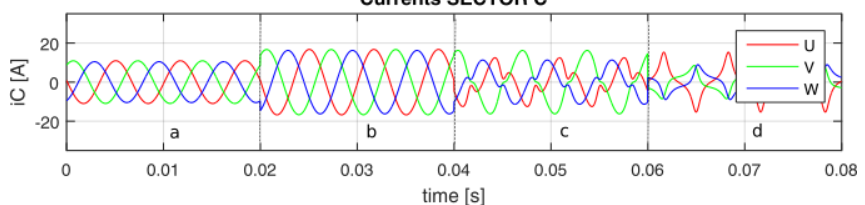

Fig. 7. Currents with $5[\mathrm{Nm}]$ torque and $25[\mathrm{~N}]$ reference radial force. Healthy machine (a), open windings behaviour with healthy machine control (b), radial force fault tolerant control (c), fault tolerant radial force control at no load (d).

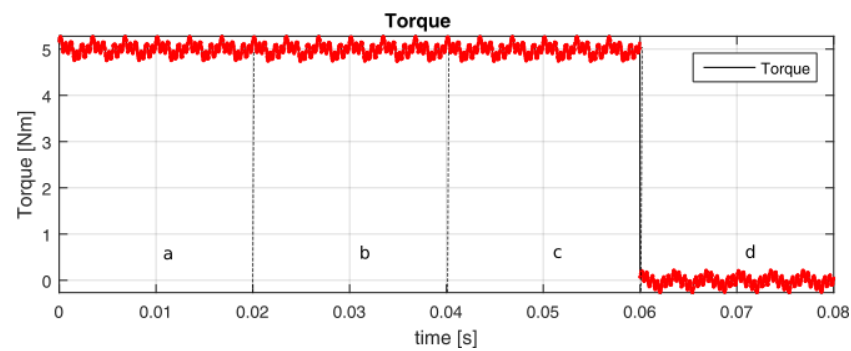

Fig. 8. Machine torque when the reference force is $25[\mathrm{~N}]$. The torque is $5[\mathrm{Nm}](\mathrm{a}, \mathrm{b}, \mathrm{c})$ and $0[\mathrm{Nm}](\mathrm{d})$. Healthy machine (a), faulty machine without fault tolerant control (b), radial force fault tolerant control (c), radial force fault tolerant control at no load (d).

TABLE I

Main Parameters of the Analyzed Nine-Phase SPM Machine [15].

\begin{tabular}{ll}
\hline Pole number $(2 p)$ & 6 \\
PM material & NdFeB \\
kW Rating & $1.5 \mathrm{~kW}$ \\
Turn/coil & 22 \\
No Load Flux/sector & $0.026 \mathrm{~Wb}$ \\
Rated Speed & $3000 \mathrm{rpm}$ \\
Torque constant & $0.128 \mathrm{Nm} / \mathrm{A}$ \\
Voltage constant & $6.022 \mathrm{~V} / \mathrm{krpm}$ \\
Phase resistance $\left(\mathrm{R}_{\mathrm{ph}}\right)$ & $0.0808 \mathrm{Ohm}$ \\
d-axis Inductance/sector $(\mathrm{Ld})$ & $0.445 \mathrm{mH}(@ 1 \mathrm{~A})$ \\
q-axis Inductance/sector $(\mathrm{Lq})$ & $0.442 \mathrm{mH}(@ 1 \mathrm{~A})$ \\
\hline Outer Stator diameter & $95 \mathrm{~mm}$ \\
Axial length & $91 \mathrm{~mm}$ \\
Air-gap length & $1 \mathrm{~mm}$ \\
Magnets thickness & $4 \mathrm{~mm}$
\end{tabular}


temporary one and a worse machine behaviour can be accepted. Furthermore, in a closed loop control it is possible to effectively improve the radial force control. Instead, Fig. 8 shows that the torque always follows its reference value, independently from the radial force control .

The FE simulations validate the analytical model and the radial force fault tolerant control in case of one sector open winding fault in a triple three-phase SPM sectored machine.

\section{CONCLUSION}

A new model of a triple three phase sectored SPM machine under open winding fault condition has been developed. The machine control has been improved to manage this fault. The proposed fault tolerant control technique shows how to take into account of the dependency of the radial force control from the torque one, dependency that arise when one three-phase subsystem is open. In this way it is possible to overcome the radial force appearing in case of fault or still control it as desired. The radial force fault tolerant control has been verified by FE analysis, and some solutions to improve the control performance have been proposed. The obtained results are essential to improve the fault tolerant performance of the multi three-phase sectored SPM machines.

\section{REFERENCES}

[1] A. Tani, Y. Gritli, M. Mengoni, L. Zarri, G. Sala, A. Bellini and G. Serra, "Detection of magnet demagnetization and high-resistance connections in five-phase surface-mounted permanent magnet generators," Diagnostics for Electrical Machines, Power Electronics and Drives (SDEMPED), 2015 IEEE 10th International Symposium on, Guarda, Portugal, 2015, pp. 487-493.

[2] A. Tani, G. Serra, M. Mengoni, L. Zarri, G. Rini and D. Casadei, "Dynamic stator current sharing in quadruple three-phase induction motor drives," Industrial Electronics Society, IECON 2013 - 39th Annual Conference of the IEEE, Vienna, Austria, 2013, pp. 51735178.

[3] A. Tani, M. Mengoni, L. Zarri, G. Serra and D. Casadei, "Control of multiphase induction motors with an odd number of phases under open-circuit phase faults," in IEEE Transactions on Power Electronics, vol. 27, no. 2, pp. 565-577, Feb. 2012.

[4] A. Galassini, A. Costabeber, C. Gerada, G. Buticchi and D. Barater, "A modular speed-drooped system for high reliability integrated modular motor drives," in IEEE Transactions on Industry Applications, vol. 52, no. 4, pp. 3124-3132, July-Aug. 2016.

[5] G. Valente, L. Papini, A. Formentini, C. Gerada and P. Zanchetta, "Radial force control of multi-sector permanent magnet machines," 2016 XXII International Conference on Electrical Machines (ICEM), Lausanne, Switzerland, 2016, pp. 2595-2601.

[6] L. Alberti and N. Bianchi, "Impact of winding arrangement in dual 3phase induction motor for fault tolerant applications," Electrical Machines (ICEM), 2010 XIX International Conference on, Rome, Italy, 2010, pp. 1-6.

[7] M. Barcaro, N. Bianchi and F. Magnussen, "Analysis and tests of a dual three-phase 12-slot 10-pole permanent-magnet motor, " in IEEE Transactions on Industry Applications, vol. 46, no. 6, pp. 2355-2362, Nov.-Dec. 2010.

[8] M. Barcaro, N. Bianchi and F. Magnussen, "Faulty operations of a PM fractional-slot machine with a dual three-phase winding," in IEEE Trans. Ind. Electron., vol. 58, no. 9, pp.3825 -3832, 2011.

[9] S. Serri, A. Tani and G. Serra, "Analytical model of radial forces considering mutual effects between torque and levitation current space vectors in 5-phase PM bearingless motors," Industrial Electronics Society, IECON 2013 - 39th Annual Conference of the IEEE, Vienna, Austria, 2013, pp. 5142-5147.
[10] S. Serri, A. Tani and G. Serra, "A method for non-linear analysis and calculation of torque and radial forces in permanent magnet multiphase bearingless motors," Power Electronics, Electrical Drives, Automation and Motion (SPEEDAM), 2012 International Symposium on, Sorrento, Italy, 2012, pp. 75-82.

[11] Z. Q. Zhu, D. Ishak, D. Howe and J. Chen, "Unbalanced magnetic forces in permanent-magnet brushless machines with diametrically asymmetric phase windings," in IEEE Transactions on Industry Applications, vol. 43, no. 6, pp. 1544-1553, Nov.-Dec. 2007.

[12] Z. Q. Zhu, M. L. Mohd Jamil and L. J. Wu, "Influence of slot and pole number combinations on unbalanced magnetic force in PM machines with diametrically asymmetric windings," in IEEE Transactions on Industry Applications, vol. 49, no. 1, pp. 19-30, Jan.-Feb. 2013.

[13] Z. Q. Zhu, Z. P. Xia, L. J. Wu and G. W. Jewell, "Analytical modeling and finite-element computation of radial vibration force in fractional-slot permanent-magnet brushless machines," in IEEE Transactions on Industry Applications, vol. 46, no. 5, pp. 1908-1918, Sept.-Oct. 2010.

[14] B. Lapôtre, N. Takorabet, F. Meibody-Tabar, J. Fontchastagner, R. Lateb and J. D. Silva, "New model of radial force determination in bearingless motor," in IEEE Transactions on Magnetics, vol. 51, no. 3, pp. 1-4, March 2015.

[15] G. Sala, D. Gerada, C. Gerada and A. Tani, "Radial force control for triple three-phase sectored SPM machines. Part I: machine model," to be presented in: 2017 IEEE Workshop on Electrical Machines Design, Control and Diagnosis (WEMDCD), Nottingham, United Kingdom, 2017.

\section{BIOGRAPHIES}

Giacomo Sala received the M. Sc. degree in Electrical Engineering, with honors, in 2014 from the University of Bologna, Bologna, Italy. Since 2014 he has been working toward the Ph.D. degree at the Department of Electrical, Electronic and Information Engineering, University of Bologna. His research interests include fault tolerant and sensorless control of multiphase drives, and fault diagnosis of electrical machines.

David Gerada received the B.Eng.(Hons.) degree in electrical engineering from the University of Malta, Malta in 2007 and the Ph.D. degree in high-speed electrical machines from the University of Nottingham, Nottingham, UK in 2012. From 2007-2015 he was with the R\&D Department at Cummins Generator Technologies, Stamford, UK, first as an Electrical Machine Design Engineer (2007-2011) and then as a Senior Electrical Machine Design Engineer and Innovation Leader (2011-2016). In 2016 he joined the University of Nottingham as a Senior Research Fellow in Electrical Machines. His research interests include high speed machines, traction machines, use of novel materials, and multiphysics-based optimization of electrical machines. Dr. Gerada is a Chartered Engineer in the U.K. and a member of the Institution of Engineering and Technology.

Chris Gerada (SM'14) received the Ph.D. degree in numerical modeling of electrical machines from The University of Nottingham, Nottingham, U.K., in 2005. He was a Researcher with The University of Nottingham, working on high-performance electrical drives and design and modeling of electromagnetic actuators for aerospace applications. $\mathrm{He}$ became a Lecturer in Electrical Machines in 2008, an Associate Professor in 2011, and a Professor in Electrical Machines in 2013 at The University of Nottingham. He currently holds the Royal Academy of Engineering/Cummins Chair in Electrical Machines at The University of Nottingham. His research interests include the design and modeling of highperformance electric drives and machines. Prof. Gerada is an Associate Editor for the IEEE TRANSACTIONS ON INDUSTRY APPLICATIONS and is the Chair of the IEEE Industrial Electronics Society Electrical Machines Technical committee.

Angelo Tani was born in Faenza, Italy, in 1963. He received the M. Sc. in Electrical Engineering, with honors, from the University of Bologna, Bologna, Italy, in 1988. Currently he is an Associate Professor with the Department of Electric, Electronic and Information Engineering, University of Bologna. He has authored more than 150 journals and conference proceedings. His current activities include multiphase motor drives, ac/ac matrix converters, and field weakening strategies for induction motor drives. 